\title{
The concept of Personally Oriented Education in the Process of Training of Veterinary Medicine Specialists
}

\author{
T. M. Karchevska \\ Podilskyi State Agrarian and Technical University, Kamianets-Podilskyi, Ukraine \\ Corresponding author. E-mail: ktmkp2015@gmail.com
}

Paper received 21.10.19; Accepted for publication 08.11.19.

\section{https://doi.org/10.31174/SEND-PP2019-208VII85-06}

\begin{abstract}
The article covers the essential aspects of the concept of personally oriented education. Key points of this concept are presented in the context of psychological training and formation of future veterinary medicine doctors. Emphasis is placed on the main psychological aspects and peculiarities of the training of veterinary specialists, with the specific nature of this profession taken into account.
\end{abstract}

Keywords: concept, vocational training, veterinary medicine specialist, principle of personal orientation.

Introduction. At the current stage of educational development, almost all countries have realized the need to introduce models of personally-oriented education into the training of future professionals, where the student is the key figure of vocational training; during the learning process it is necessary to take into account their needs, motives, goals, abilities, activity, intelligence and other individually-specific psychological features.A brief overview of publications on the issue in question.From the standpoint of present-day national and foreign pedagogy, one can distinguish a number of concepts of personalityoriented education from different positions, which do not contradict each other, as T.I.Koval notes [1], but put the emphasis on different sides of the educational process. The ideal of these concepts is the subject of education - a capable and free person, who is proactive, enterprising, developed, confident in him/ herself and in his/ her own right, able to navigate the diversity of contradictions in the modern world and has strategies of creative activity and possesses professional intuition.

A very accurate interpretation of the concept of personally oriented education is given by S. V Paniukov (after T.I. Koval) [1], who notes that this is an education that is aimed at the learner, as the fundamental value of the entire educational process, it helps create the conditions for the formation and manifestation of the learners' personal qualities, develops their thinking, forms a creative, active, driven personality, satisfies their cognitive and spiritual needs, develops their intelligence, social and communicative abilities, self-education skills, selfdevelopment, and is focused on the need of society for specialists who are capable of independent knowledge acquisition, retraining and adaptation to new social conditions. This concept allows to change the approach to professional training of future specialists in any branch through the development of their own thinking, intelligence, becoming a creative and independent personality. T.I. Koval [1] notes in his writings that the contradictions that have arisen in the higher education system have hindered the improvement of the quality of professional training of future professionals - the main criterion of education. There is an urgent need for changes in the approaches to the training and education of future professionals as individuals, capable of changing and improving society, independently setting and achieving goals, thinking logically and creatively, consciously evaluating their activity on the basis of analysis and decision making.
Such an important task of vocational training can only be fulfilled if new educational models, oriented towards the personally-oriented training paradigm, centered on the needs and interests of the future specialist, are introduced into the educational process. In this case, the student should not only acquire knowledge, skills and expertise, master the best practice patterns, but also adopt a creative approach to their implementation, develop stable cognitive interests and motives of learning, the need for constant self-education. Z.I.Slepkan [2] The main spheres of students' life are professional education, personal growth and self-affirmation, development of intellectual potential, spiritual enrichment, moral, and aesthetic and physical self-improvement. G.O. Ball [3] regards the individual as a subject of professional culture, whose integral part is professional competence. Preparation for professional activity through the lens of personality development is to be considered in the context of humanization of vocational education, whose leading idea is to orient the goals, content, forms and methods of education to the learner's personality, and harmonize it. N.I. Machinska [4] states that the principle of personal orientation helps find, support, and develop an individual and provide him/her with the mechanisms of self-realization, self-development, self-education, adaptation, etc., necessary for the formation of original personality image and dialogical and safe interaction with people, nature, culture, and civilization.

In order to implement this principle, the author proposes to use certain rules: it is necessary to treat students as independent entities that are able to study voluntarily, at their own will and free choice; equip the student's personality with the mechanisms of comprehension, communication, cooperation; to promote the formation and development of students in various activities, creative abilities necessary for self-realization of the individual in practical work, scientific research, artistic and other kinds of activity, etc. L.P. Kachalova [5] examines the implementation of a person-centered approach through the prism of pedagogical support, and emphasizes that it is based on processes aimed at unlocking personal potential and creating conditions for self-actualization of the individual. The contemporary, non-traditional, self-oriented education paradigm developed by I.A. Bekh has an anthropocentric character. It objectively replaced the cultural-centered paradigm. Its system-forming factor is not education, but personality, individuality as a unique personality [6]. 
Objective. The purpose of the article is to analyze the problem of personally oriented training and evaluate the possibility of its application in the system of professional training of future veterinary medicine doctors.

Materials and methods. In the process of writing the paper, professional publication references and pedagogical research methods have been used.

Results and Discussion. Thus, we can say that the principle of personal orientation requires the disclosure and full development of the individual in accordance with the requirements of modern progress. For the future veterinary medicine specialist, as well as for any specialist in any other sphere, professional competence is the necessary amount of knowledge and practical skills that are necessary for successful completion of all tasks of professional activity, competitiveness in the labor market and free orientation in the information environment. Personality education should be aimed at training a specialist who possesses not only the methods, means, technique of his or her business, but also the values, ideals, and holistic professional culture. All this fully relates to the professional training of veterinary specialists, which is somewhat specifici. At present, market relations place rather stringent requirements on the level of qualification and competence of veterinary doctors, which necessitates the approximation of the system of their preparation to the world level. Today, the responsibility of veterinary specialists to society is growing sharply, because not only the welfare but also the lives of many people and animals depend on the decision taken by the veterinarian. Therefore, the training of future specialists in this field requires special responsibility from the teacher, who must take into account a number of psychological aspects in the teaching and training process, prepare a truly highly qualified specialist. The teacher in the process of professional training of the future veterinarian should constantly develop a positive attitude and convey to each student significant examples of motivation to work in the chosen profession, taking into account all the psychological aspects, which in turn will allow to develop and stimulate professional abilities. In the process of such training, it should be borne in mind that future veterinary professionals should not only correctly make a clinical diagnosis, but also master the laws of marketing and management, the laws of the market, organize their work, as well as be able to build relationships with colleagues, owners of animals, etc. Recently, an active process of reforming veterinary education has been taking place in our country. New methods combined with traditional ones are an important lever in reforming the veterinary specialist training system.

Therefore, the professional training of veterinary specialists requires an analytical approach in the process of training with the obligatory application of basic pedagogical and psychological concepts, namely, the concept of personally oriented education. One of its aspects is also aesthetic education in the preparation of future veterinary medicine specialists. the development of an aesthetic culture of the individual, able not only to reveal the creative abilities of each student, but also to create an atmosphere of empathy, compassion for the sick animal, and in this regard, the formation of skills to control their own feelings and emotions, and positively interact with others.
It is common knowledge that the emotional state of an individual significantly influences his/her intellectual activity. Without the basic components of intelligence: memory, attention, observation, motivation, it is impossible to form neither as a full-fledged person nor as a highly skilled specialist in any field, including veterinary medicine. In this regard, it is possible to determine the theoretical foundations of the formation of specialist culture in the works of I.A. Ziaziun [7], who believes that the content of the training and its specific forms should be developed on the basis of humanistic ideas about the future activities of the desired target qualities of the specialist as an individual, his/her professional experience and thinking. Such a training system should ensure the background for the necessary cultural professional new formations. On the basis of the totality of such ideas, it is proposed to formulate a variant of the model of the future specialist, where professionalism is the main criterion for creative solution of tasks of future professional activity, development of professional culture and self-awareness. The profession of veterinary doctor places high demands on the psychosensory sphere of the individual. After all, he/she is responsible for the health of the animal, as well as the human being, in addition, veterinary doctors bear moral responsibility to the owner of the animal for a possible negative course of the disease. Therefore, the future specialist should cultivate such qualities as: responsiveness, balance, friendliness, and patience. A high level of responsibility for the health of animals and humans contributes to the formation of such personal qualities as: intuition, discipline, determination, observation, diligence, perseverance and willingness to perform work in any, often adverse conditions. This also determines the development of responsibility, accuracy and self-control in relation to their own actions: when making a diagnosis, using medicines, performing medical procedures, conducting surgical interventions, writing prescriptions, etc. Diverse activities of a veterinary specialist require active thinking when solving different tasks, often having to act in extreme conditions, when one needs to quickly decide on the best actions for this particular case and in the situation at hand. This requires inventiveness, developed on the basis of memory and operational logical thinking, self-control and ingenuity based on emotional maturity. To develop all these qualities in each personality of the future veterinary specialist in addition to providing fundamental knowledge should become a primary task of every teacher, because it is thanks to the concept of personally oriented education that the future veterinary medicine specialist will be able to master the professional mobility in the production industry, the ability to adapt quickly to production science and modern technologies in the conditions of market transformations according to European requirements.

Conclusions. Thus, according to a person-centered conception of education in the learning process, priority must be given to the development of the individual, that is, knowledge, skills and expertise are recognized by scholars not as the purpose of learning, but as means of its development and formation to become a subject of activity and social relations. Personally oriented training should become a leading concept in the education of future veterinary medicine doctors, which will encourage them to 
continuous self-improvement and allow the formation of a highly qualified and competitive specialist of the Europe- an level veterinary industry.

\section{REFERENCES}

1. Koval T.I. Requirements for Personally Oriented Professional Training in Information Technologies of Future ManagersEconomists // Pedagogical Process: (Theory and Practice): Pedagogy and Psychology: Collection of Scientific Papers (edited by S. Sysoeva). K. Ekmo, Issue 1, 2004. P.51-66.

2. Slekpan Z.I. Scientific Principles of Pedagogical Process in Higher School. K.: Higher School, 2005. P. 24.

3. Ball G.O. "Personality Culture" Category in the Analysis of General and Vocational Education. // Pedagogy and Psychology of Vocational Education: Research Findings and Prospects: Collection of Scientific Papers / edited by I.A. Ziaziun and N.G. Nichkalo. Kyiv, 2003. pp. 51-61.

4. Machinska N.I. Principles of Content Selection of Pedagogy Modules for Teachers Training Colleges // Pedagogical Pro- cess: (Theory and Practice): Pedagogy and Psychology: Collection of Scientific Papers (edited by S. Sysoeva). K. Ekmo, Issue 1, 2004. P.73-80.

5. Kachalova L.P., Kachalov D.V., Kachalov A.V. PersonOriented Approach in Education: Pedagogy of Personality. Shadrinsk: Publishing House "Shadrinsky Publishing House", 2007. P. 65.

6. Bekh I.D. Educating the Personality: Book. 2: PersonCentered Approach: Scientific and Practical Background. K.: Lybid, 2003. 344 p.

7. Ziaziun I.A. Humanistic Paradigm in Education // Higher Education in Ukraine. Realities, Tendencies, and Prospects of Development. Part 1. New Higher Education Program. Kyiv, 1996. pp. 8-12. 